\title{
Leucemia mielomonocítica crónica
}

\section{Chronic myelomonocytic leukemia}

\author{
Jecsmael César Báez-Herrera '
}

Báez-Herrera J. Leucemia mielomonocítica crónica. 2021;34(2):

86. https://doi.org/10.36393/spmi.v34i2.603

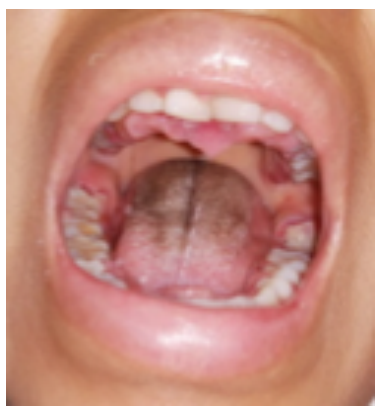

Figura I.

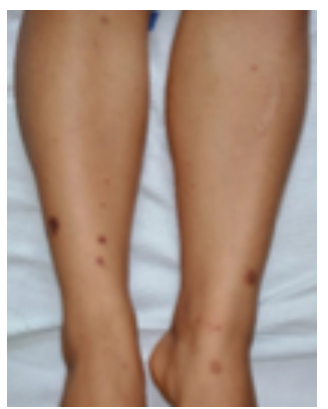

Figura 2.

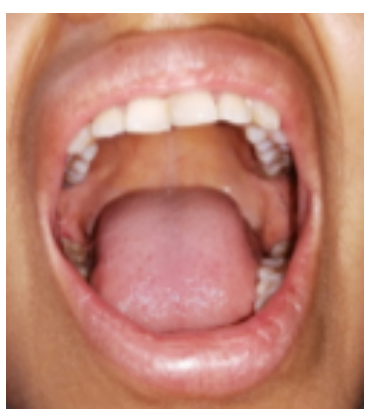

Figura 3.
Mujer de 27 años, sin antecedentes de importancia, con fatiga, palidez e incremento progresivo del tamaño de las encías desde hace tres meses. Al examen físico se evidenció un sobrecrecimiento gingival global (Figura 1) y lesiones maculopapulares violáceas en ambas piernas (Figura 2). En los exámenes auxiliares se halló leucocitosis 54 060/ $\mathrm{mm}^{3}$ con $80 \%$ de blastos, hemoglobina $6,2 \mathrm{gr} / \mathrm{dl}$, plaquetas $10000 / \mathrm{mm}^{3}$; citometría de flujo de sangre periférica: incremento de la serie monocítica hasta $67,26 \%$ con rangos displásicos y blastos mieloides en 1,08\%; gen BCR-ABL negativo. Se realizó biopsia de piel cuyo estudio histológico informó infiltración dermal por células redondas basófilas de aspecto blástico, compatible con leucemia cutis. La paciente recibió quimioterapia: ifosfamida, carboplatino y etopósido. Cursó con neutropenia febril, recibió cobertura antibiótica de amplio espectro con evolución favorable; $\mathrm{y}$, fue dada de alta a los dieciocho días posteriores al tratamiento quimioterápico con notable resolución del crecimiento gingival (Figura 3).

La leucemia mielomonocítica crónica (LMMC) es una neoplasia maligna peculiar que muestra superposición de características entre un síndrome mieloproliferativo y mielodisplásico, más frecuente en adultos mayores varones, con hallazgos clínicos inespecíficos, síntomas constitucionales (fiebre, pérdida de peso, sudoración nocturna) y con mayor frecuencia de síntomas producto de

Médico residente de medicina interna. Facultad de Medicina, Universidad Nacional Mayor de San Marcos. Hospital Nacional EsSalud Guillermo Almenara Irigoyen, Lima, Perú. las citopenias (fatiga, palidez, sangrado, infecciones). Las infiltraciones leucémicas cutáneas nodulares o infiltración gingival se ven ocasionalmente. El trasplante alogénico de médula ósea es el único tratamiento con intención curativa de la LMMC pero se ve limitada por la edad avanzada de los pacientes. Otras estrategias incluyen agentes hipometilantes, citotóxicos, entre otros. El pronóstico de la enfermedad es malo y la sobrevida se encuentra entre los 16 a 18 meses a partir del diagnóstico con riesgo de transformación a leucemia mieloide aguda de hasta el 30\%.

\section{REFERENCIAS BIBLIOGRÁFICAS}

1. Thomopoulos TP, Bouhlal A, Papageorgius SG, Pappa V. (2020). Chronic myelomonocytic luekemia - a review. Expert Review of Hematology. 2021;14(I): 59-77. DOI: https://doi.org/I0.1080/I74740 86.2021 .1860004$.

2. Micheva I, Chervenkov T, Ruseva C, Gercheva L. Chronic myelomonocytic leukemia - review and clinical experience of the Hematology Department UMHAT St. Marina Varna.J of IMAB. 2016. Jan-Mar;22(I): I09I-I095.DOI:http://dx.doi.org/I 0.5272/jimab.20I6 221.1091

3. Quintero-Sierra Y, Mustelier-Celza GL, Hernández-Padrón C, et al. Leucemia mielomonocítica crónica. Rev Cubana Hematol Inmunol Hemoter. 20I4;30(4). URL disponible en: http://www.revhematologia. sld.cu/index.php/hih/article/view//89.

\section{CORRESPONDENCIA}

Jecsmael César Báez Herrera

jcbh_1995@hotmail.com

Fecha de recepción: 03-04-202I.

Fecha de aceptación: 07-06-202I.

Financiamiento: por el autor.

Conflicto de interés: ninguno, según el autor. 